\title{
A economia política do conhecimento *
}

\author{
Elizabeth Moura Oliveira ${ }^{* *}$ \\ Luiz Filgueiras ${ }^{* * *}$
}

\begin{abstract}
Resumo
O objetivo deste texto é o de discutir, no interior do paradigma marxista, o que se considera ser o aspecto central do debate sobre a "Economia do Conhecimento", e que antecede todos os demais, qual seja: a natureza e o significado da mercadoria-conhecimento. Mais especificamente, o propósito é evidenciar o caráter rentista da "nova economia", a partir da análise crítica da tese da desmedida do valor (Eleutério Prado), e da tese da ausência de valor nas mercadorias-conhecimento (Rodrigo Teixeira e Tomas Rotta). Evidenciamos a necessidade de se avançar para níveis menos abstratos de análise, particularmente, no sentido de relacionar o rentismo às reconfigurações contemporâneas do imperialismo e da dependência.
\end{abstract}

Palavras-chave: Mercadoria-conhecimento; Renda-conhecimento; Economia política do conhecimento.

\begin{abstract}
The political economy of knowledge

The objective of this text is to discuss, within the Marxist paradigm, what is considered the central aspect of the debate on the "Knowledge Economy", and that antecedes all others, which is the nature and meaning of the knowledge-commodity. More specifically, the purpose is to highlight the rentism of the "new economy", based on the critical analysis of the thesis of unmeasurable value (Eleuterio Prado), and the thesis about the valueless knowledge-commodity (Rodrigo Teixeira and Tomas Rotta). We defend the need to advance to less abstract levels of analysis, particularly in the sense of relating the rent-seeking to contemporary reconfigurations of imperialism and dependency.
\end{abstract}

Keywords: Knowledge-commodity; Knowledge-rent; Political economy of knowledge.

JEL B14, P16, O34.

\section{Introdução}

Recentemente, muitas visões entusiastas, pode-se dizer "fetichizadas", da Economia do Conhecimento e da Informação vêm ganhando notoriedade, expressando-se nos mais curiosos prognósticos, como, por exemplo, a ideia de Rifkin (2014), segundo a qual o recente surgimento da Internet das Coisas estaria levando o capitalismo ao ocaso, ao mesmo tempo em que este mesmo capitalismo decadente estaria dando luz a uma extraordinária "economia de compartilhamento". Nessa perspectiva, tendo em vista a crescente importância econômica da informação e do conhecimento, e considerando que os custos marginais destes bens estão se aproximando de zero, estaríamos caminhando em direção a uma economia colaborativa, que o

\footnotetext{
* Artigo recebido em 26 de março de 2018 e aprovado em 31 de maio de 2019.

${ }^{* *}$ Professora adjunta da Faculdade de Economia da Universidade Federal da Bahia (FE-UFBA), Salvador, BA, Brasil. E-mail: elizabethmoura@ hotmail.com. ORCID: https://orcid.org/0000-0002-3997-4940,

${ }^{* * *}$ Professor Titular da Faculdade de Economia da Universidade Federal da Bahia (FE-UFBA), Salvador, BA, Brasil. E-mail: luizmfil@gmail.com. ORCID: https://orcid.org/0000-0001-8922-0410.
} 
autor chama de "sociedade do custo marginal zero". O problema desse tipo de visão não é exatamente acreditar no potencial criativo das novas tecnologias, mas sim concebê-las como inerentemente virtuosas e com acesso e uso democráticos; é não perceber ou ignorar a economia política que as define, com todas as suas graves contradições.

Desse modo, diferentemente de Rifkin, o ponto de vista aqui adotado compreende a Economia do Conhecimento como o processo abrangente de mercantilização e monopolização do conhecimento e da informação; portanto, a rota de compreensão de seus fundamentos passa bem longe da ideia, cada vez mais difundida, de que se estaria diante do ocaso do capitalismo e de constituição de uma "economia colaborativa".

O mercado do conhecimento se tornou um lócus dos mais privilegiados na acumulação capitalista global. Esses mercados, que caracterizam a nova economia, são constituídos pelo que podemos chamar de mercadorias-conhecimento ${ }^{1}$, conforme o faz Teixeira (2009), ou, ainda, de mercadorias-informação, ou seja, mercadorias constituídas tão somente por bens intelectuais, ou de outro modo, por bens imateriais ${ }^{2}$. De fato, a mercadoria-conhecimento tornou-se a principal base material do capitalismo dos nossos dias, dando origem a um novo rentismo situado na vanguarda do desenvolvimento capitalista.

Apesar da imensa variedade de valores de uso, as mercadorias-conhecimento possuem uma característica em comum muito bem definida: seus custos de reprodução são nulos ou quase nulos - mesmo que eventualmente tenham altos custos de produção da primeira unidade - e dependem invariavelmente de mecanismos (técnicos ou jurídicos, por exemplo) de proteção à propriedade intelectual. A inexistência de custos de reprodução significa a inexistência de custos com força de trabalho e insumos. Com isso, pode-se afirmar que a característica decisiva das mercadorias-conhecimento é a inexistência do próprio processo de reprodução.

Partimos da premissa de que o sentido maior da discussão sobre a Economia do Conhecimento é o fato de ela se constituir, no capitalismo contemporâneo, num dos principais eixos do processo de aguçamento da assimetria global de poder. Do ponto de vista estritamente econômico $^{3}$, o pressuposto é o de que a monopolização dos conhecimentos estratégicos ${ }^{4}$

(1) Todo o universo dos softwares, como sistemas operacionais, dados, automação industrial e serviços em nuvem, franquias e pacotes de dados de internet, artigos acadêmicos, códigos genéticos e outros resultados da pesquisa científica básica, fórmulas químicas na indústria farmacêutica, bens da indústria de direitos autorais, da comunicação, cultural e do entretenimento, como filmes, séries, jogos esportivos, games, programas de TV, músicas e outras mercadorias (desde que estejam digitalizadas), serviços financeiros digitais, entre muitos outros.

(2) Essa descrição de bens imateriais não deve se remeter ao debate acerca do trabalho imaterial, que tem entre seus proponentes autores como Hardt e Negri (2002) e Gorz (2005), e entre seus críticos, Prado (2005a) e Carcanholo e Medeiros (2012). As análises em torno do trabalho imaterial são centradas na esfera da produção. No caso do nosso texto, o foco principal (apesar de não exclusivo) é a esfera da circulação.

(3) Na verdade, sob nosso ponto de vista, para muito além da dominação econômica, a Economia do Conhecimento está no cerne da hegemonia estadunidense, abarcando os mais diversos campos de batalha (político, militar, científico, tecnológico, informacional). Nossa concepção sobre a hegemonia estadunidense por ser encontrada em Ceceña (2005). Trata-se de uma agenda de pesquisa com grande potencial a ser explorado.

(4) Consideramos como estratégicas as mercadorias-conhecimento que definem padrões de consumo e de produção em âmbito global. Um exemplo paradigmático é o Windows, sistema operacional da Microsoft, que tem uma participação no mercado mundial em torno de $90 \%$ (Zuazo, 2018). 
reproduz em nível avançado as hierarquias e desigualdades estruturais da divisão internacional do trabalho, o que pode ser compreendido a partir de uma dupla explicação articulada entre si.

A primeira explicação é o fato de que as atividades econômicas relacionadas à comercialização do conhecimento possuem um caráter rentista, ou seja, são baseadas essencialmente não na produção direta de valor, mas sim na apropriação do valor gerado socialmente.

A segunda é a de que esta mercantilização/monopolização é liderada pelo grande capital dos países imperialistas. As maiores transnacionais das indústrias constitutivas do atual paradigma tecnológico intensivo em conhecimento - Tecnologias da Informação e da Comunicação (TIC) e biotecnologia - são, sobretudo, dos Estados Unidos. Considerando mais especificamente as megacorporações estadunidenses da economia digital - Apple, Amazon, Microsoft, Alphabet, Facebook - pode-se observar que não apenas registram os maiores valores de mercado na área de tecnologia, como também em relação às empresas de todos os demais setores, como JP Morgan Chase \& Co e Exxon Mobil (As 10 empresas..., 2018).

A capitalização de mercado média das multinacionais tecnológicas (as que comercializam mercadorias-conhecimento) é quase três vezes maior do que a de multinacionais de outros ramos. Em 2015, as 10 maiores - das quais, 6 são dos EUA, 1 da Alemanha, 1 do Japão, 1 da Coreia do Sul e 1 chinesa - representavam 26\% da capitalização de mercado total no ranking das 100 maiores, algo que pode ser atribuído ao monopólio de intangíveis como marca e outras propriedades intelectuais, de acordo com a United Nations Conference on Trade and Development (2017).

O peso e o dinamismo das mercadorias-conhecimento no principal país imperialista (Estados Unidos) nas últimas décadas também podem ser observados empiricamente num inovador trabalho de Rotta (2018). O autor fez uma análise da evolução da acumulação improdutiva nos Estados Unidos no período entre 1947 e 2011, a partir de uma classificação das atividades econômicas em produtivas ou improdutivas, a partir de categorias marxistas. Isso significa que ele faz uma distinção entre atividades que produzem mais-valia (atividades produtivas) e atividades que não a produzem (atividades improdutivas). Outros estudos já tinham feito essa diferenciação, mas, de acordo com o autor, a produção de conhecimento e informação foi tratada de forma inédita como atividade improdutiva, metodologia fundamentada teoricamente na interpretação destes bens como mercadorias sem valor. $\mathrm{O}$ resultado do estudo é o de que, após um período de predominância da acumulação produtiva no pós-guerra, a acumulação improdutiva passou a ser preponderante, devido especialmente ao rápido crescimento das finanças e da produção do conhecimento.

O resultado, portanto, do caráter simultaneamente rentista e imperialista é a geração de uma forma inédita de dependência ${ }^{5}$ na periferia do sistema capitalista fundamentada, em sua

(5) Apoiamo-nos aqui na concepção de dependência formulada por Marini (1973, p. 111). Esta categoria deve ser "entendida como una relación de subordinación entre naciones formalmente independientes, en cuyo marco las relaciones de producción de las naciones subordinadas son modificadas o recreadas para asegurar la reproducción ampliada de la dependência". 
dimensão econômica, nesse novo mecanismo de transferência de valor (renda-conhecimento) a favor do imperialismo ${ }^{6}$. Com isso, defendemos que a Economia do Conhecimento renova e aprofunda a natureza dependente do capitalismo periférico e acaba por reproduzir historicamente o processo de superexploração da força de trabalho.

Uma demonstração ampla de todos esses pressupostos requer uma metodologia que abarque diversos níveis analíticos, iniciando num plano mais abstrato (a análise teórica da mercadoria-conhecimento, focando, particularmente no seu caráter rentista) e progredindo gradualmente para um patamar de maior concretude, com a incorporação da questão da dependência no padrão de desenvolvimento atual de determinado país.

Propomos, no presente artigo, desenvolver precisamente esse primeiro momento metodológico, ou seja, a análise e evidenciação eminentemente teórica do caráter rentista da comercialização do conhecimento (que corresponde à "primeira explicação" das fortes assimetrias de poder no plano internacional exposta acima). Necessariamente, essa discussão será feita a partir da teoria do valor de Marx, sem a qual não seria possível apreender os nexos lógico-históricos entre a monopolização imperialista do conhecimento estratégico e a nova forma de dependência com a consequente reprodução histórica da superexploração da força de trabalho. Observe-se que tanto a categoria do imperialismo quanto da dependência situam-se nos marcos da teoria marxista do valor.

Esse empreendimento será realizado por meio da análise crítica comparativa de duas visões acerca do problema que, a despeito de fundamentarem integralmente suas linhas de raciocínio e argumentação nos escritos de Marx, representam duas teses parcialmente distintas e até mesmo contrapostas em determinados pontos - em particular, remetendo a duas interpretações distintas acerca do estatuto e alcance da teoria do valor nessa "nova economia". Trata-se da tese da Pós-Grande Indústria, de Prado (2005a), e da tese da mercantilização do conhecimento como autonomização do capital na esfera não financeira, de Teixeira e Rotta (2012). O conjunto dos trabalhos destes autores nos oferece uma valiosa contribuição na medida em que não apenas apontam para o rentismo inerente à mercantilização dos bens intelectuais (nosso maior objeto de interesse), como submetem suas respectivas hipóteses ao escrutínio das categorias marxianas, permitindo-nos a apreciação crítica de dois pontos de vista distintos.

A primeira delas - a tese da Pós-Grande Indústria ${ }^{7}$ - formulada originalmente por Ruy Fausto e desenvolvida por Prado, defende que o fenômeno (da mercantilização do conhecimento) teria sido um produto dos desdobramentos do progresso tecnológico ocorrido na Grande Indústria, um modo de produção que teria sido superado nos países centrais. Na passagem da era fordista para o capitalismo contemporâneo, teria havido uma transmutação na

(6) A concepção de imperialismo aqui adotada se refere a um estágio superior do capitalismo que surgiu com a emergência dos monopólios e do capital financeiro (Lenin, 2012).

(7) A mercantilização do conhecimento não é o objeto central da tese da Pós-Grande Indústria, mas está subtendida como uma característica definidora do objeto de análise principal (o capitalismo contemporâneo). 
função do conhecimento no processo de acumulação do capital, de modo que, mais do que um elemento subjacente ao avanço das forças produtivas, ele teria passado a ser a própria fonte de criação do valor - materializado pelo trabalho intelectual. Nesse sentido, o trabalho medido pelo tempo, antes, suporte único do valor, teria se reduzido a uma base miserável na criação de riqueza, pari passu ao surgimento e expansão do valor desmedido gerado pelo trabalho intelectual. No que diz respeito ao tipo de renda, o autor faz uma analogia entre conhecimento e capital de empréstimo, concluindo que a renda do conhecimento é análoga ao juro (Prado, 2005a).

A segunda tese - a de Teixeira e Rotta (2012) - está fundamentada na interpretação da mercantilização do conhecimento como uma das dimensões possíveis do processo de autonomização do capital que se manifesta na esfera não-financeira. Em particular, entendem que não existiria valor algum na produção capitalista do conhecimento, de modo que seu rendimento seria, em termos marxistas, integralmente "renda", o que radicalizaria ainda mais a sua obsessão por apropriação de valor criado pelos capitais industriais. Nessa visão, a rendaconhecimento seria análoga à renda fundiária (Teixeira, 2009).

Além desta Introdução, este texto é constituído de mais três seções. Nas duas primeiras apresentam-se, respectivamente e de forma crítica, as duas visões acima mencionadas. Na última, confrontam-se essas duas visões, destacando-se seus pontos de unidade e divergência, bem como suas limitações e respectivas contribuições para se avançar no conhecimento do problema - evidenciando-se algumas implicações dessa nova forma-mercadoria.

\section{Pós-grande indústria e renda-conhecimento análoga aos juros}

Em Prado (2005a, 2005b, 2010), podemos identificar a questão da mercantilização do conhecimento em meio às suas análises a respeito da mudança histórica na natureza do suporte material do capital fixo, que deixou de ser tangível para ser imaterial. Tais transformações não expressam o mero surgimento de um fenômeno no interior do atual estágio histórico do capitalismo; mais do que isso, é parte constitutiva da própria forma que assumiu o modo de produção capitalista a partir dos anos 1970. A compreensão do fenômeno requer, na verdade, a compreensão das transformações do sistema em sua totalidade.

A interpretação de Prado (2005b) se distingue da interpretação corrente na literatura marxista mais convencional segundo a qual o capitalismo teria entrado numa nova fase a partir dos anos 1970, cuja principal característica seria a (pre)dominância financeira. Haveria um problema metodológico crucial nessa literatura, segundo ele, que seria a realização de uma abordagem macroeconômica e historiográfica do desenvolvimento do modo de produção capitalista. O caminho adequado não seria, portanto, a "delimitação de fases de desenvolvimento", mas sim, "indagar se a consciência crítica está ou não na presença de um novo modo de produção, uma nova forma no interior do modo de produção capitalista" (2005b, p. 49. Grifos nossos).

Para isso, seu ponto de partida são as formulações de Ruy Fausto a respeito do surgimento da Pós-Grande Indústria. Porém, Prado vai além da perspectiva de Fausto: ao invés 
de restringir sua análise às transformações nos limites do processo produtivo, considera o processo global de valorização do capital (Teixeira, 2009).

Mas o que seria a Pós-Grande Indústria? De acordo com Prado, trata-se do terceiro momento do modo de produção capitalista iniciado no pós-segunda guerra e que se consolidou efetivamente a partir da década de 1970; uma nova forma de produção decorrente de uma transformação na natureza de seu capital fixo, o qual tem deixado de ser predominantemente tangível para se tornar predominantemente imaterial. As duas principais consequências têm sido (i) uma mudança na forma de subsunção do trabalho ao capital, que passou de material para intelectual e (ii) a desmedida do valor.

$\mathrm{Na}$ Grande Indústria, o progresso tecnológico tem a função vital de reduzir o tempo de trabalho necessário. De fato, seu sistema de máquinas com altas aplicações tecnológicas tornou o processo de trabalho extremamente objetivo e assim, mais produtivo, reduzindo o trabalhador a um simples apêndice. Segundo Prado, ainda que a mais-valia provenha exclusivamente do trabalho vivo nesta forma de produção, o progressivo desenvolvimento tecnológico da Grande Indústria acaba por, contraditoriamente, reduzir o trabalho medido pelo tempo a uma base miserável na criação de riqueza. Nas últimas décadas, a perda de importância do trabalho medido pelo tempo em face da expansão da ciência no processo produtivo culminou, desse modo, na superação dialética da Grande Indústria, dando lugar ao surgimento da Pós-Grande Indústria.

É verdade que não se pode negar que o aumento da produtividade nos setores produtivos tecnologicamente mais avançados reduziu extraordinariamente o tempo de trabalho necessário, ou seja, sua dimensão quantitativa. Mas Prado concebe essa perda de importância como algo relacionado a uma transformação qualitativa: a crescente importância da ciência no processo de criação de valor na Pós-Grande Indústria ou, em outras palavras, um ganho de importância do trabalho intelectual. Ele se apoia na seguinte afirmação que Marx faz nos Grundrisse:

No entanto, à medida que a grande indústria se desenvolve, a criação da riqueza efetiva passa a depender menos do tempo de trabalho e do quantum de trabalho empregado que do poder dos agentes postos em movimento durante o tempo de trabalho, poder que - sua poderosa efetividade -, por sua vez, não tem nenhuma relação com o tempo de trabalho imediato que custa sua produção, mas que depende, ao contrário, do nível geral da ciência e do progresso da tecnologia, ou da aplicação dessa ciência à produção. [...] O roubo de tempo de trabalho alheio, sobre o qual a riqueza atual se baseia, aparece como fundamento miserável em comparação com esse novo fundamento desenvolvido, criado por meio da própria grande indústria (Marx, 2011, p. 587-588. Grifos nossos).

Sua ideia, portanto, é que essa transformação qualitativa - a mudança na base material privilegiada do capital, que deixou de ser tangível e passou a ser imaterial (a ciência) - promove outras duas transformações fundamentais no próprio modo de produção (já mencionadas brevemente acima): (i) uma se refere à tese apresentada da desmedida do valor, segundo a qual, "em razão do crescente conteúdo intelectual do trabalho, o valor encontra-se desmedido"; e (ii) 
a outra, associada à primeira, se refere à forma de subsunção do trabalho, que antes era formal, real e material, e agora se tornou formal, real e intelectual.

Essas transformações podem ser compreendidas da seguinte forma. A dupla transformação na substância do valor (forte redução do trabalho abstrato e crescimento da importância da ciência) tornou o tempo de trabalho uma medida inadequada para mensurá-lo, pois a "produtividade" da ciência - dependente do trabalho intelectual - não guarda uma relação simples e direta com a economia temporal. Essa "produtividade" está calcada em processos de trabalho com um forte componente subjetivo, como a capacidade criativa e comunicativa do trabalhador, o que cria "empecilhos para a homogeneização dos tempos de trabalho" (Prado, 2005a, p. 53). A dificuldade em se abstrair uma substância comum que iguala os mais diversos trabalhos concretos torna inadequada a mensuração do valor a partir do tempo de trabalho intelectual. Para que fique mais claro, vale citar as palavras do autor:

Porém, não se trata de dizer que a ciência e a tecnologia em si mesmas, independentemente do trabalho, são agora as produtoras do valor. Quem produz valor é ainda o trabalho, mas este agora, enquanto trabalho concreto, transformou-se em trabalho criativo, inteligente, cognoscitivo, etc., ou seja, atividade produtiva que exige a mobilização de conhecimentos, os quais, por sua vez, são partes da força produtiva social - do intelecto coletivo da sociedade. Em consequência, dada a relativa irrelevância do tempo de trabalho e a proeminência da qualidade desse tempo, a ciência e a tecnologia tornam-se produtoras de "valor" por meio de trabalho. Assim, mesmo se o tempo de trabalho socialmente necessário é suprimido como medida da riqueza capitalista, esta tem ainda de ser medida. $\mathrm{O}$ valor desmedido continua dependente de um processo social de redução - mas este não é mais uma operação puramente quantitativa. (Prado, 2005a, p. 89. Grifos nossos).

Consequentemente, a forma de subsunção do trabalho ao capital sofre uma mutação: ela deixa de ser material para se tornar intelectual. Essa nova subordinação não deixa de ser formal e real, afinal de contas, o trabalhador continua vendendo sua força de trabalho ao capitalista (subsunção formal) e seu trabalho continua subordinado a um sistema totalizador e se dando em função de um processo de produção que foge ao seu controle (subsunção real). No entanto, tendo em vista a desmedida do valor criado pelo trabalho intelectual, já não basta ao capital comandar o tempo de trabalho; agora é preciso também controlar o tempo de nãotrabalho. Esse controle não se confunde com aquele exercido no período da Grande Indústria, quando o trabalhador era controlado também na condição de consumidor. No capitalismo contemporâneo, a subsunção intelectual se tornou mais totalitária: envolve o controle do trabalhador enquanto trabalhador, consumidor e agente político e social, por meio do neoliberalismo ${ }^{8}$.

Mas voltemos à análise que o autor faz a respeito das transformações na base material do capitalismo contemporâneo. Na Grande Indústria, os principais ativos de capital fixo são

(8) Prado (2016, 2018), se apoia na concepção de neoliberalismo de Dardot e Laval (2016, p. 17). Segundo estes autores, neoliberalismo é, acima de tudo, uma racionalidade cuja propriedade fundamental é a "generalização da concorrência como forma de conduta e da empresa como modelo de subjetivação". 
tangíveis, que funcionam sob uma lógica mecânica e que são constituídos de modo a elevar tanto quanto possível a subordinação do trabalho ao capital, ou seja, as máquinas devem ser capazes de subtrair ao máximo a subjetividade do trabalhador no processo produtivo. No que diz respeito à Pós-Grande Indústria, Prado afirma que os capitais fixos são fundamentalmente os ativos intangíveis; a ciência não está mais meramente incorporada nas máquinas, tal como ocorre na Grande Indústria, mas se tornou ela própria a forma mais valorizada do capital, presente tanto nos sistemas de informação e controle quanto no intelecto dos trabalhadores. A lógica de funcionamento deixou de ser mecânica e passou a ser cibernética, ou seja, ao invés de um sistema onde valia a relação linear de causa e efeito, agora surgem as relações recursivas, as interações entre múltiplos e distintos agentes que dão origem às propriedades emergentes e a uma incerteza mais profunda.

Desse modo, uma reviravolta substancial do capitalismo contemporâneo (pós-grande indústria, na visão de Prado) é a progressiva retirada do conhecimento científico do domínio público, transformando-o em objeto de privatização. Se durante toda a história do capitalismo até os anos 1970, a ciência pública foi funcional à acumulação capitalista (o escopo dos objetos patenteáveis era outro), hoje ocorre precisamente o contrário. A ciência tornou-se o ativo mais valorizado, de modo que sua existência enquanto capital requer, logicamente, sua apropriação privada.

Todos esses bens mercantilizados possuem algo em comum. Não foi simplesmente uma mudança quantitativa dos tipos de bens mercantilizados; não houve apenas uma expansão das fronteiras do mercado, com a incorporação de uma maior variedade de valores de uso. A Pós-Grande Indústria operou especialmente uma transformação qualitativa: o conhecimento enquanto mercadoria possui um caráter absolutamente sui generis; sendo um bem intangível, ele pode ser reproduzido praticamente sem custos, por mais cara que tenha sido a sua concepção.

Vejamos o seguinte: o conhecimento, enquanto não privatizado, possui todas as características de um bem público. Bens públicos, segundo a teoria econômica neoclássica, são simultaneamente não-disputáveis e não-excluíveis. A não rivalidade, de fato, é uma característica irrevogável dessa espécie de bem, faz parte de sua própria natureza, pois não há como o consumo de conhecimento reduzir a sua disponibilidade para terceiros.

Mas a exclusividade, ao contrário do que defende a teoria neoclássica, não é uma característica "natural" de um bem, mas sim um atributo definido politicamente. Ou melhor, a não exclusividade depende da decisão do Estado a respeito de leis que definam se determinado bem não-rival pertence ao âmbito público ou privado. Portanto, a garantia dada pelo Estado de um direito de propriedade privada transforma o conhecimento num bem não rival e excluível ${ }^{9}$.

(9) Paulani (2016) diz que, na teoria convencional, os bens não rivais e excluíveis são chamados de toll goods (bem pedagiados). 
Assim, a mercantilização do conhecimento depende totalmente do Estado para a instituição de direitos de propriedade intelectual, sejam patentes, direitos autorais etc. Sem o Estado, a comercialização do conhecimento se inviabiliza, pois, na ausência de DPI, após a primeira unidade vendida, o comprador pode perfeitamente difundir tal conhecimento (pirataria) para toda a sociedade anulando todo o potencial mercado consumidor da mercadoria em questão. Prado explica esta questão da seguinte forma:

A teoria econômica neoclássica define como públicos os bens cujo uso não é passível de disputa, ou seja, cujo uso por uns não impede o uso por outros e que, simultaneamente, não podem ser privatizados devido as características que lhe são inerentes. Têm a primeira característica os valores de uso cujo custo de reprodução é zero ou desprezível. Possuem supostamente o segundo predicado os bens que podem ser obtidos sem a necessidade de direto pagamento pelo uso. Mas esse último não é, a rigor, um atributo apenas do bem em si mesmo, mas depende também das instituições que regulam o modo de seu emprego, o que faz dele um atributo de caráter político. [...] Decorre daí que quase não há bens inerentemente públicos ou, dito de outro modo, bens que não possam ser privatizados por meio de legislação que provém de decisões políticas. (Prado, 2005a, p. 112-113).

Dessa característica do conhecimento, segue uma mudança da maior importância na forma de comercialização: ele não é vendido como uma mercadoria convencional, ou seja, normalmente mantém-se o direito de propriedade e vende-se tão somente o direito de uso ${ }^{10}$. Prado faz uma leitura bastante particular em torno dessa questão: se o que se vende é apenas um direito de uso, o que na verdade seria um empréstimo, e se o conhecimento é uma forma específica de capital, então, o conhecimento é um tipo de capital de empréstimo.

O capitalista não pode vender o conhecimento como mercadoria, mas terá de transferir o direito de usá-lo por meio de um contrato que resguarda o seu próprio direito de propriedade por meio de certas garantias jurídicas. Dito de outro modo, tem necessariamente de considerá-lo como capital de empréstimo. (Prado, 2005a, p. 107).

Consequentemente, na visão do autor, o capitalista que empresta as mercadoriasconhecimento ao capitalista industrial é, na verdade, um capitalista financeiro. Marx é citado para ajudar a esclarecer isso: "todo o capital emprestado, qualquer que seja sua forma e como quer que o reembolso seja modificado pela natureza de seu valor de uso, é sempre uma forma particular do capital monetário" (apud Prado, 2005a, p. 108). Na visão de Prado, a mercadoriaconhecimento é emprestada como capital e, portanto, como valor (e não como valor de uso), cumprindo, assim, a função de gerar mais-valia, não importando a forma como isso acontece

(10) No caso dos mercados de propriedade intelectual - como o mercado de patentes ou o mercado de marcas - há a transferência não de direitos de uso, mas sim de propriedade. Esses casos tornaram-se muito comuns para fins de especulação financeira ou para potenciais ganhos litigiosos. Certamente que esses casos fazem parte de uma dinâmica mais ampla que engloba a mercantilização do conhecimento, mas a venda de DPI não pode ser confundida com a venda de direitos de uso ou de acesso aos bens protegidos por patentes ou copyright, por exemplo. Não faz parte dos objetivos deste artigo tratar da comercialização dos direitos de propriedade intelectual. 
no processo produtivo. Dado que este excedente é gerado com a contribuição do capital monetário emprestado, este é em parte retornado ao capitalista financeiro como juros.

\section{A autonomização do capital e a renda-conhecimento como análoga à renda da terra}

Seguindo o mesmo movimento de Prado, Teixeira e Rotta (2012) analisam as transformações no capitalismo atual a partir de mudanças no processo de valorização na esfera produtiva. Mas diferentemente do primeiro, que concebe o conhecimento como capital de empréstimo, Teixeira e Prado o concebem como mercadoria sem valor. Eles desenvolvem uma concepção ampliada do princípio da autonomização do capital na perspectiva do que eles chamam de "nova teoria da produção e da distribuição de mercadorias-conhecimento sem valor e da renda-conhecimento", sem conceber qualquer modificação na teoria do valor, "especialmente quanto ao seu fundamento, segundo o qual o valor das mercadorias é determinado pelo tempo de trabalho abstrato necessário à sua reprodução" (Teixeira, 2009, p. 455).

Esse ponto não é nada trivial. A explicitação da validade histórica da teoria do valortrabalho de Marx importa na medida em que legitima também a própria capacidade analítica da teoria marxista no contexto da "Economia do Conhecimento", contrapondo-se aos teóricos do fim do trabalho, como, por exemplo, André Gorz e Claus Offe (Carcanholo; Medeiros, 2012). Tal evidência - mesmo nessa sociedade do conhecimento - acaba por mostrar que os rendimentos derivados da mercantilização do conhecimento se originam totalmente de uma redistribuição do mais-valor social, pois a mercadoria-conhecimento é incapaz, dada a sua natureza, de gerar e/ou transferir qualquer valor.

Teixeira e Rotta retomam a discussão da financeirização, mostrando que uma abordagem marxista, num nível mais abstrato de análise, requer a consideração do conceito de capital em Marx. De forma bastante sintética, pode-se dizer que, mais do que valor auto expansivo, ou seja, mais do que considerar o capital como sujeito do processo de valorização, o ponto principal para eles é compreender dialeticamente que o capital é uma forma social abstrata que, ao mesmo tempo em que tende a expelir o trabalho produtivo de seu processo de valorização, não tem como se valorizar sem ele. O capital procura se afastar de seu suporte material, apesar de não ser possível romper com esse vínculo. Trata-se aqui, obviamente, da lei tendencial da autonomização do capital.

Com isso, o termo mais adequado para apreender as transformações do capitalismo contemporâneo, segundo Teixeira e Rotta, não seria a financeirização, mas sim a autonomização. A financeirização, na verdade, seria apenas a manifestação da autonomização do capital através das finanças; no entanto, dizem eles, esse é apenas um "lado da moeda". Os autores mostram que essa autonomização também ocorre na dimensão produtiva, que é precisamente a mercantilização do conhecimento. Assim, o capitalismo contemporâneo, em 
sua essência, pode ser compreendido a partir da análise dessa dupla autonomização: a financeira e a produtiva.

Eles chegaram a essa conclusão por meio da análise da natureza do conhecimento enquanto mercadoria: bens de caráter não rival e que dispensam tanto recursos materiais quanto trabalho abstrato para sua reprodução. Eis o ponto de ruptura com a ideia de Prado: enquanto para este o conhecimento necessariamente tem que ser considerado um capital de empréstimo, já que se trata de um valor de uso não disputável, Teixeira e Rotta concebe-o como uma mercadoria sem valor, dada a inexigibilidade do trabalho (intelectual ou não) para a sua reprodução. O próprio Marx é citado para sustentar esse argumento: "[T]he value of commodities is determined not by the time that it took to be originally produced but by the labor time necessary to its reproduction" (Marx apud Teixeira e Rotta, 2012, p. 8. Ênfase dos autores). A monopolização e comercialização de bens intelectuais (mercadorias sem valor) é o que fundamenta a tese da segunda forma de autonomização do capital.

Da mesma maneira que Prado, os autores obviamente reconhecem que, sendo um bem não disputável, o conhecimento não é produzido a fim de se comercializar seu direito de propriedade, mas sim para vender direitos de uso. Nesse caso, o rendimento auferido pelo licenciamento ou transferência do direito de uso da mercadoria sem valor não pode ser lucro, mas sim um tipo de renda. Se o conhecimento é um bem não-rival e excluível, então a sua produção capitalista é incontornavelmente uma atividade rentista. É claro que, se Teixeira e Rotta discordam da ideia de que o conhecimento seja capital de empréstimo, dadas as características e a função da mercadoria-conhecimento, eles não poderiam comparar a renda oriunda do conhecimento aos juros, mas sim à renda da terra ${ }^{11}$.

Eles argumentam que, diferentemente do capital portador de juros que possui valor, aquilo que eles chamam de moderno capital portador de renda não possui. A chave analítica para captar a distinção entre estas duas categorias e, assim, determinar se a renda-conhecimento é análoga aos juros ou à renda da terra, reside na consideração da relação dialética posição/pressuposição de cada forma social (capital portador de juros e moderno capital portador de renda). Em outras palavras, é preciso conhecer a diferença entre capital-mercadoria e mercadoria-capital, que pode ser compreendida conforme a síntese que os autores fizeram com base no Livro III, d'O Capital, de Marx:

(1) Commodity-capital functions as a commodity and not as capital. It is only capital while considering the global circuit, but it is sold as a commodity and not as capital. It circulates as a use-value (e.g. means of production and productive inputs).

(2) Capital-commodity is commodity as capital. It is a sum of value that has the use-value of creating surplus-value. Despite being a lent commodity it does not figure as a use-value

(11) Prado aparentemente também faz uma analogia entre a renda do conhecimento e a renda da terra. A convergência entre essa passagem e a tese defendida por Teixeira e Rotta não chegou a ser explorada por estes autores. 
but rather as a value (e.g. interest-bearing capital). It is money or a commodity as possible capital that becomes a commodity. (Teixeira e Rotta, 2012, p. 11. Destaques no original).

O conhecimento, no caso, representa um capital-mercadoria, pois quando adentra o circuito produtivo, ele tem um caráter meramente qualitativo, está posto como valor de uso (como a terra), sendo que seu valor está apenas pressuposto. Seu valor de uso é elevar a força produtiva do trabalho.

Por outro lado, o capital de empréstimo, seja na forma monetária ou na forma mercadoria, está posto para o capitalista industrial - ou seja, para o tomador do empréstimo como valor e pressuposto como valor de uso. Ele tem um caráter quantitativo, com a função de gerar mais valor. O pagamento de juros só é devido quando se empresta uma soma de valor, o que não é o caso da mercadoria-conhecimento, pois como se viu acima, se ela não requer trabalho vivo para a sua reprodução, ela necessariamente é uma mercadoria sem valor (como a terra), não podendo se configurar em capital, pois capital necessariamente é valor.

Para ilustrar essa diferença, Teixeira e Rotta explicam o caso do empréstimo de uma máquina cuja produtividade supera a da concorrência. Deve-se fazer uma observação adicional para a melhor clareza da ilustração: a maior produtividade da máquina aqui não pode se dever meramente a uma maior intensidade tecnológica, mas à incorporação de alguma mercadoriaconhecimento, como por exemplo, uma máquina automatizada por um software.

Neste caso específico, trata-se simultaneamente de um capital-mercadoria (pelo simples fato de ser uma máquina) e de uma mercadoria-capital (pelo fato de ser uma máquina mais produtiva). Como isso é possível? Primeiramente, uma máquina, independentemente de seu nível de produtividade, está posta como valor e pressuposta como valor de uso, pois figura como capital (cujo valor de uso é gerar mais-valia), de modo que parte do sobrelucro gerado pelo capitalista industrial se converterá em juros. Este é o aspecto quantitativo da máquina em questão.

Mas caso essa máquina possua uma capacidade produtiva superior devido a uma força monopolizável e não reprodutível pelo trabalho (aspecto qualitativo) - como é o caso do exemplo dado - que lhe permita estabelecer seu preço de produção abaixo do preço de mercado, então outra parte deste sobrelucro se converterá em renda-conhecimento. Essa máquina mais produtiva, portanto, possibilita a geração concomitante de dois tipos de renda: (i) os juros, devido ao capital de empréstimo (a máquina) e (ii) a renda-conhecimento, devido ao empréstimo da mercadoria-conhecimento exclusiva e sem valor embutida na máquina. Essa renda-conhecimento é determinada, portanto, pela renda diferencial, de forma análoga a um dos tipos de renda da terra. Vejamos a citação abaixo a respeito desta última:

O exemplo de Marx é o seguinte: suponha que a maioria das fábricas num país seja impulsionada por máquinas a vapor, e uma minoria o seja por quedas-d'água naturais. Suponha ainda que os capitalistas que utilizem a queda d'água tenham um preço de produção mais baixo, e que em decorrência disso, como a maioria utiliza a outra técnica (máquinas a vapor), o preço social de produção seja mais alto que o preço individual de 
produção para os que utilizam a queda d'água. Esta diferença gera então um sobrelucro para estes, que é a diferença entre o preço social de produção, ao qual a mercadoria será efetivamente vendida, e o preço individual, mais baixo, ao qual estes proprietários específicos a produzem. (Teixeira, 2009, p. 435-436).

O sobrelucro aqui obtido se converterá especificamente em renda da terra, e não em outro tipo de renda, pelo fato de a queda d'água ser uma força natural monopolizável e não reprodutível. Ela cumpre única e exclusivamente a função de aumentar a força produtiva do trabalho, estando posta como valor de uso e somente pressuposta como valor. Ela não é a fonte de criação de valor, mas sim o suporte material para a sua criação.

O conhecimento, assim como a queda d'água, também pode cumprir o papel de aumentar a força produtiva do trabalho. Apesar de não ser uma força natural, é uma força social monopolizável que, caso participe do processo produtivo, estará posta como valor de uso. Apesar de ser reprodutível, não é o caso de empregar quantidade de trabalho para isso. Como o sobrelucro que o conhecimento contribui para gerar resulta do estabelecimento do preço de produção abaixo do preço de mercado, então a renda-conhecimento é determinada, em grande medida, pela renda diferencial.

Mais do que somente renda diferencial, a renda-conhecimento tem outros determinantes. A renda absoluta é derivada da mera propriedade da terra e representa uma parcela da mais-valia agrícola; assim, ela existe mesmo que não haja renda diferencial, ou seja, mesmo que todas as terras tenham a mesma produtividade. A mera propriedade da terra não garante a obtenção de uma renda, mas permite a cobrança de um pagamento para a liberação de seu acesso. No caso dos bens intelectuais, a renda absoluta parece fazer todo o sentido quando pensamos na nova infraestrutura das Tecnologias de Informação e Comunicação (TIC), que cada vez mais deixa de ser, em determinado patamar mínimo, uma fonte de ganhos competitivos para ser investimento básico "obrigatório", sem o qual nem mesmo os lucros normais seriam possíveis.

A renda de monopólio, por sua vez, também é devida à mera propriedade da terra e não possui qualquer relação com o seu nível de produtividade. Relaciona-se, isso sim, com a disposição ou capacidade de pagar de quem adquire a mercadoria. Ela permite o estabelecimento de um sobrepreço exclusivamente devido ao monopólio. Note-se que enquanto o limite máximo da renda absoluta depende da capacidade de aumentar a exploração da força de trabalho, o limite máximo da renda de monopólio depende da capacidade ou disposição a pagar do consumidor.

\section{Considerações sobre as abordagens teóricas da mercadoria-conhecimento}

Pode-se dizer que, em comum, as duas visões aqui discutidas consideram a mercadoriaconhecimento $^{12}$ como a principal base material do capitalismo dos nossos dias, bem como

(12) Prado costuma utilizar não o termo mercadoria-conhecimento, mas, sim, conhecimento-capital. No entanto, ainda assim o termo pode ser utilizado, pois o autor trabalha justamente com a questão da comercialização dos direitos de acesso ao 
deixam patente a força e a grandeza de um novo rentismo daí derivado. E mais, em ambas está presente a ideia de que a mercantilização dos bens intelectuais é uma forma de acumulação irremediavelmente rentista. E se renda significa, obviamente, apropriação de valor, então a monopolização do conhecimento resulta na intensificação do processo de transferência de valor entre capitais individuais.

No entanto, divergem completamente em outro quesito. Prado defende a ideia da desmedida do valor, segundo a qual o trabalho medido pelo tempo teria deixado de ser a única e exclusiva substância do valor na Pós-Grande Indústria, dando espaço e primazia ao conhecimento $^{13}$. Teixeira e Rotta entendem que a acumulação capitalista pautada na produção do conhecimento tem um caráter exclusivamente rentista, pois consideram que a mercadoriaconhecimento não tem valor e que, por isso, o trabalho abstrato continua sendo a única e exclusiva fonte de geração de mais-valia. Essa divergência conduz a outra diferença no que diz respeito ao tipo de analogia que se faz com a renda oriunda da comercialização do acesso ao conhecimento: enquanto Prado diz ser análoga aos juros, Teixeira e Rotta dizem ser análoga à renda da terra.

Para além destas convergências e divergências entre os autores acima, existem algumas questões que serão problematizadas na sequência: a primeira é um aspecto eminentemente teórico sobre a analogia entre a renda do conhecimento e os juros, a segunda é uma observação sobre a atual forma histórica da relação entre a financeirização e a mercantilização do conhecimento e, por fim, discutiremos a importância de se incorporar categorias menos abstratas - como imperialismo e dependência - para a superação de limitações pontuais nas análises da mercantilização do conhecimento.

\subsection{A analogia entre a renda-conhecimento e os juros}

Há uma questão paradoxal nas formulações de Prado: a analogia entre renda do conhecimento e juros como desdobramento da desmedida do valor. Caso seja legítimo recorrer aos escritos de Marx no Livro III (1894, p. 174), d'O Capital (como o fez Teixeira e Rotta), a qual afirma que o valor das mercadorias é determinado pelo tempo de trabalho necessário à sua reprodução e não à sua produção original, então, há uma contradição na tese da Pós-Grande Indústria: para que o trabalho intelectual fosse capaz de produzir valor novo, ele teria que ser requerido sempre que fosse necessário "reproduzir" uma unidade adicional da mercadoriaconhecimento.

Porém, considerando que Prado admite que os custos de reprodução do conhecimento privatizado são nulos ou quase nulos, conforme citação abaixo, então ele concorda com a ideia de que o trabalho intelectual só é necessário para a produção da unidade original do produto.

\footnotetext{
conhecimento como uma especificidade do capitalismo contemporâneo ou, em outras palavras, a mercantilização do conhecimento.

(13) Prado afirma que o conhecimento também depende do trabalho, mas não do tempo de trabalho, pois este passou a ser intelectual e criativo (Prado, 2005a, p. 89), e, portanto, qualitativo, cuja produtividade não se mede temporalmente.
} 
Desse modo, sua tese da desmedida do valor postula, implicitamente, a ideia de que não precisa haver reprodução para criação de valor, pelo menos no caso da atividade intelectual.

Mas o mesmo não ocorre com os conhecimentos científicos e tecnológicos tornados capital fixo, já que, se eles têm um alto custo de produção, possuem, ao mesmo tempo, um custo de reprodução muito baixo, que se aproxima frequentemente de valores nulos. (Prado, 2005a, p. 107).

Para que a comparação com os juros fosse possível, o conhecimento teria que ser equiparável à mercadoria-dinheiro ou à outra mercadoria que também funcione como capital, ou seja, ser simultaneamente mercantilizável e dependente do trabalho para sua reprodução. No entanto, essa concomitância é inviável. O juro é o rendimento derivado da propriedade de uma soma de valor emprestada ao capital em função, seja dinheiro ou uma determinada mercadoria que funcione como capital. O que significa que o juro é um rendimento oriundo do empréstimo de algo que depende do trabalho para ser produzido e reproduzido no capitalismo.

No caso da mercadoria-conhecimento, a ausência do processo capitalista de reprodução dispensa qualquer tipo de trabalho, inclusive o trabalho intelectual. Por outro lado, mesmo considerando a tese da desmedida do valor, precisaríamos dar conta das situações onde a própria produção capitalista do conhecimento mercantilizado está ausente ${ }^{14}$, ou seja, das situações onde o conhecimento comercializado é oriundo de processos de espoliação e não oriundo do trabalho intelectual. Por tudo isso, nossa visão é a de que essa tese é irreconciliável com o caso do conhecimento na forma mercadoria.

\subsection{A relação histórico-concreta entre a financeirização e a mercantilização do conhecimento}

Na literatura a respeito do capitalismo contemporâneo, há certa hegemonização do debate pelo tema da financeirização. As mudanças mais relacionadas à esfera produtiva geralmente recebem uma abordagem de caráter principalmente histórico e de forma subordinada às mudanças na esfera financeira. Prado e Teixeira e Rotta fazem um movimento muito importante para mostrar que as transformações na esfera produtiva têm uma dimensão muito mais profunda do que se costuma reconhecer. Como discutido anteriormente, eles mostram que financeirização é a autonomização que se manifesta na dimensão financeira e a mercantilização do conhecimento é a autonomização que se expressa na dimensão produtiva. Acreditamos que esta é uma contribuição substancial, mas que, para dar conta da manifestação histórica do fenômeno, vale avançar para uma compreensão de que tem ocorrido nas últimas quatro décadas um processo de retroalimentação e uma interdependência entre ambas as formas de autonomização.

Conforme mostraram Orsi e Coriat (2006) e Coriat e Weinstein (2011), a financeirização foi um impulso fundamental para a mercantilização do conhecimento. Em outras palavras, é como se dissesse - unindo as contribuições de Teixeira e Rotta, de um lado,

(14) Faremos alguns comentários a esse respeito na última seção. 
e as de Orsi e Coriat (e Coriat e Weinstein), de outro (a despeito de estarem em distintos níveis de abstração) - que a "nova economia" promoveu um amálgama entre o novo capital portador de renda e o capital portador de juros, ou, então, que passou a haver uma retroalimentação entre os dois tipos de capital. A atividade de produção capitalista do conhecimento possui uma natureza fortemente rentista.

É preciso ressaltar que não se pode perder de vista a relação fortemente simbiótica, no plano histórico-concreto, entre a financeirização e a mercantilização do conhecimento; há uma forte interconexão entre os dois fenômenos. Essa simbiose não se confunde com as conexões entre atividades improdutivas e produtivas, que também existem. Trata-se de destacar a simbiose entre dois diferentes tipos de atividades improdutivas.

De um ponto de vista histórico, a financeirização se iniciou no início dos anos 1970, com os primeiros processos de desregulação dos mercados financeiros, antecedendo, portanto, a mercantilização do conhecimento que só se tornou sistemática após as reformas nos Estados Unidos a partir de 1980. Nesta década, a liquidez de instituições financeiras, como os fundos de pensão, foi crucial para a constituição dos primeiros mercados do conhecimento e da informação. Mas a própria financeirização é alimentada pelo crescimento do processo de "imaterialização"15 dos ativos das empresas. Essa lógica é basicamente a seguinte: quanto maior for a redução com o custo com a força de trabalho e quanto maior a capacidade de determinação de preços de monopólio - essa dupla capacidade atinge seu ápice com as mercadorias-conhecimento -, maior será a rentabilidade da empresa, o que, por sua vez, cria as bases para uma maior valorização dos seus ativos financeiros. Essa é uma espiral "sem fim": quanto maior a liquidez proporcionada pelos mercados financeiros, maior a capacidade de investimento em ativos imateriais protegidos por Direitos de Propriedade Intelectual.

Em suma, a "especialização" do capital em ativos intangíveis do conhecimento é um dos caminhos mais promissores para a valorização da empresa nos mercados de ações. Faz sentido concluir que a financeirização não seria tão extensa e abrangente se não fosse a mercantilização do conhecimento e que a própria mercantilização do conhecimento não teria ido tão longe se não fossem os ditames da especulação financeira. Nessa perspectiva, assim como é importante expor a existência de duas distintas formas de autonomização do capital, como o fizeram Teixeira e Rotta (2012), vale capturar a interdependência histórica entre ambas no capitalismo contemporâneo.

\subsection{A necessidade da incorporação do imperialismo e da dependência na análise da economia do conhecimento}

Existem alguns fenômenos de imensa relevância para a crítica da Economia Política do Conhecimento que só se tornam "perceptíveis" quando se mobiliza categorias mais concretas de análise, particularmente imperialismo, dependência e sistema interestatal

(15) Usamos o termo imaterialização não simplesmente no sentido de tornar imaterial, mas sim de tornar intelectual, não rival, virtual ou, ainda, digital. 
capitalista ${ }^{16}$. Abaixo destacamos três fenômenos que não devem ser subestimados: a proeminência das rendas absoluta e de monopólio no processo de apropriação imperialista de valor, a existência da lógica de poder estatal para além da lógica de valorização do capital como eixo do desenvolvimento científico-tecnológico e o papel crucial da espoliação no processo de acumulação capitalista no âmbito da nova economia.

\subsubsection{Proeminência das rendas absoluta e de monopólio}

Teixeira e Rotta lançaram as bases teóricas para a interpretação da renda-conhecimento como análoga à renda da terra, mostrando que assim como a propriedade fundiária, a propriedade intelectual proporciona dois tipos de renda diferencial, renda absoluta e renda de monopólio. Aqui é importante chamar a atenção para a forma como essas rendas se manifestam historicamente na nova economia: o rentismo do conhecimento do "mundo desenvolvido" repousa, acima de tudo, sobre as rendas absoluta e de monopólio, em detrimento das rendas diferenciais.

O que está em jogo no topo da hierarquia global não é o monopólio de tecnologias mais produtivas para uso próprio, mas os ganhos derivados de sua mercantilização, ou seja, as rendas (absoluta e de monopólio) oriundas da comercialização do conhecimento. Em outras palavras, o objetivo prioritário não é a obtenção de tecnologias que reduzam seu próprio tempo de trabalho individual em relação ao tempo de trabalho socialmente necessário (para fins de obtenção de rendas diferenciais), pois isto só faria sentido se se tratassem de capitais envolvidos em atividades produtivas, o que, como visto, não é o caso.

Isso importa na medida em que revela uma divisão internacional do trabalho muito bem definida: os países imperialistas detêm o monopólio das mercadorias-conhecimento estratégicas e os países dependentes mercantilizam essencialmente o conhecimento não estratégico e as mercadorias convencionais. Se considerarmos, por exemplo, a disseminação global de tecnologias digitais de produção (que são mercadorias-conhecimento estratégicas monopolizadas pelo grande capital imperialista), os ganhos de produtividade proporcionam uma vantagem competitiva (e rendas diferenciais) duplamente limitada aos países dependentes: (i) limitada no tempo, pois a tendência é a generalização progressiva das mercadoriasconhecimento que proporcionam maior produtividade, minando a fonte de sua competitividade; (ii) e limitada no espaço, pois só é possível competir com outros países

(16) O sistema interestatal capitalista, conforme concebido por Fiori (2014, p. 25), foi forjado não apenas pela lógica da acumulação do capital ou pela expansão dos mercados, mas também pela "criação do poder expansivo de alguns Estados europeus [...] que lutaram, entre si, pela conquista e monopolização de posições de poder e de acumulação de riqueza”. Segundo o autor (Fiori, p. 18), "[e]m termos estritamente lógicos, o poder é uma relação que se constitui e se define, tautologicamente, pela disputa e pela luta contínua pelo próprio poder". 
dependentes, que participam tão somente dos mercados não estratégicos do conhecimento ou dos mercados de bens e serviços convencionais.

Como discutido anteriormente, para explicar a natureza dos rendimentos oriundos da comercialização das mercadorias-conhecimento, Teixeira e Rotta fazem uma comparação entre o conhecimento e a terra, mostrando que, assim como essa última, o conhecimento não possui valor, mas somente valor de uso. Um exemplo bem trabalhado foi o caso do conhecimento utilizado para aumentar a força produtiva do trabalho, proporcionando, com isso, uma renda diferencial ao proprietário. Do ponto de vista teórico, não há o que retocar.

Mas quando, a partir das contribuições destes autores, fazemos os desdobramentos da analogia entre renda-conhecimento e renda fundiária para um nível mais concreto da análise do imperialismo, percebe-se que o que fundamenta a hegemonia econômica contemporânea dos países ricos não são as rendas diferenciais do conhecimento. Empresas como Amazon ${ }^{17}$, Google $^{18}$, Facebook ${ }^{19}$ e Microsoft ${ }^{20}$ - que ocupam, respectivamente, o $1^{\circ}, 3^{\circ}, 5^{\circ}$ e $7^{\circ}$ lugares no ranking das marcas mais valiosas do mundo (Brand Finance, 2018) - tendem a concentrar-se quase que exclusivamente em atividades improdutivas.

Atualmente, o mero acesso ou uso das TIC proporciona ganhos de competitividade cada vez menores e, consequentemente, as rendas diferenciais vão perdendo cada vez mais relevância no interior deste paradigma tecnológico, tendo em vista a crescente digitalização da economia. A partir de uma distinta abordagem teórica, a ideia de commoditização digital de Arbache (2016) relacionada à popularização do uso das tecnologias digitais converge com o nosso argumento. Segundo o autor, o que dá vantagem competitiva a um país não é mais o acesso e o uso dessas tecnologias, mas a capacidade de desenvolvê-las, bem como a capacidade "de desenvolver e gerir novos modelos, plataformas e padrões de negócios digitais".

Por outro lado, a robustez da hegemonia econômica e tecnológica do imperialismo não se sustenta simplesmente na obtenção de lucros extraordinários das atividades produtivas (atividades que produzem mais-valia). Do ponto de vista econômico, o imperialismo se sustenta, sobretudo, nas atividades improdutivas e, portanto, muito mais na apropriação do mais-valor social do que na sua produção. E nesse sentido, para o grande capital imperialista, o que realmente está em jogo é a obtenção de rendas absolutas e de monopólio.

Observe-se que a propriedade das mercadorias-conhecimento estratégicas não está nas mãos do capital funcionante. Assim como o proprietário de terras aufere uma renda absoluta independentemente da existência de rendas diferenciais - uma renda que se deve

(17) A Amazon atua em diversos ramos de mercadorias-conhecimento como no comércio eletrônico de livros digitais, na prestação de serviços online para varejistas, na publicidade online e em serviços de computação em nuvem (Azevedo; Selmi, 2018).

(18) A principal fonte de receita do Google é a publicidade na internet (Dona do Google..., 2018).

(19) Quase toda a receita do Facebook é obtida no mercado de publicidade na internet (Gutierrez, 2018).

(20) As principais fontes de receita da Microsoft são aplicativos de escritório (linha Office), serviços em nuvem, Windows (seu sistema operacional), games e publicidade na internet (Como a Microsoft..., 2018). 
fundamentalmente, à propriedade fundiária - o proprietário das mercadorias-conhecimento também obtém a renda absoluta quer ela sirva ou não para a obtenção de ganhos de competitividade dos capitais subordinados. A digitalização da atividade produtiva dá um ganho de produtividade apenas temporário aos primeiros usuários das mercadorias-conhecimento; ao fim e ao cabo, os grandes beneficiários permanentes são os monopolistas do conhecimento.

Além da renda absoluta, outro tipo de renda que ganhou uma proeminência extraordinária no capitalismo contemporâneo, na perspectiva das mercadorias-conhecimento, foi a renda de monopólio proporcionada pela marca. A mercadoria-conhecimento, quando utilizada no ciclo de reprodução de um bem rival, atua no aumento da diferença entre o preço de produção e o preço de mercado, e isso não necessariamente ocorre por meio da redução do primeiro, ou seja, por meio do aumento da força produtiva. Sem que se eleve a taxa de exploração da força de trabalho, é possível aumentar essa diferença por meio do estabelecimento de preços de monopólio (como no caso da marca).

A ilustração mais recorrente é o caso do capitalista produtor dos melhores vinhos, cuja superioridade deriva de fatores exclusivamente naturais: terras de melhor qualidade que produzem melhores uvas. Isso lhe permite vendê-lo por um preço acima do preço de produção sem que tenha promovido necessariamente nenhuma economia de trabalho. No caso do conhecimento, as marcas cumprem perfeitamente esse papel. Segundo Paulani (2016, p. 531), o objetivo das marcas "não é simplesmente ajudar a vender a mercadoria, mas 'gerar valor', produzir um price premium, ou, em nossos termos aqui, garantir uma renda de monopólio". Portanto, as marcas não aumentam a diferença entre preço individual de produção e preço de mercado por meio do aumento direto da taxa de exploração, mas sim, pelo seu poder de estabelecer um preço de monopólio.

A marca não deixou de cumprir, em tese, a função de evitar o problema da seleção adversa e de expandir seu market share, mas hoje, mais do que isso, ela cumpre a função de ser ela mesma a própria mercadoria - uma mercadoria espetáculo ${ }^{21}$.

Klein (2002) expõe de forma inequívoca a mudança de um paradigma no qual a marca dava suporte ao produto para o seu inverso: atualmente é o produto o que dá suporte à marca, tornando-se um ativo estratégico dos mais importantes das grandes corporações. Ela ganhou autonomia do produto original e deu origem a um expressivo dinamismo aos mercados de licenciamento de marca. Exemplos de grandes participantes desses mercados são Coca-Cola, Disney, Nike, times esportivos e empresas de setores os mais diversos, conforme a Associação Brasileira de Licenciamento (2017).

A importância da marca pode ser percebida também através do espaço que o chamado branding (gestão da marca) passou a ocupar nas grandes transnacionais, evidenciados nos expressivos aumentos em gastos com publicidade. Ao mesmo tempo, enquanto a marca se

(21) O termo "espetáculo" remete à definição proposta por Debord (1967): “o espetáculo não é um conjunto de imagens, mas uma relação social entre pessoas, mediatizada por imagens". 
tornava um ativo mais valioso, a fabricação dos produtos passou a ser cada vez mais terceirizada (Klein, 2002). A afirmação de Phil Knight, na época CEO da Nike, é bastante sintomática: "não há mais valor em produzir coisas. O valor é agregado pela pesquisa cuidadosa, pela inovação e pelo marketing" (Katz apud Klein, 2002, p. 221).

\subsubsection{Economia do Conhecimento e imperialismo}

Prado explica a origem ou o modo como se constituiu a Pós-Grande Indústria a partir do progresso técnico inerente à lógica da Grande Indústria. Seu próprio modus operandi teria alterado progressiva e dialeticamente a proporção entre ciência e trabalho abstrato na produção da riqueza ao longo do tempo, tendo em vista a necessidade intrínseca do capital de objetivar cada vez mais o processo produtivo. É inegável que o progresso técnico faz parte da dinâmica interna da Grande Indústria, mas acreditamos que é crucial a incorporação de elementos históricos que tiveram um papel da maior importância na aceleração desse processo e que não necessariamente se confundem com a evolução desse modo de produção (Grande Indústria).

O autor chega a mencionar aspectos histórico-concretos cruciais, conforme citação abaixo:

A pós-grande indústria requer, pois, o monopólio de recursos essenciais para a reprodução da sociedade contemporânea, tais como, por exemplo, os programas de computador, as fórmulas para a fabricação de remédios, as tecnologias para a produção de sementes, etc. É evidente que esses recursos tendem a se concentrar no controle de algumas poucas corporações gigantes e multinacionais, cujo poder tende a ultrapassar, então, o da grande maioria dos Estados nacionais. Em consequência, esse poder privado desmedido não pode ser mantido sem o apoio dos Estados nacionais das potencias imperialistas. Note-se que o recrudescimento do imperialismo no final do século XX e no princípio do século XXI tem como uma de suas motivações principais garantir os direitos de propriedade intelectual por todo o planeta. (Prado, 2005a, p. 113).

No entanto, o Estado, apesar de seu papel imprescindível para a existência dos monopólios intelectuais, aparece como inteiramente subordinado à lógica de valorização do capital. É preciso incorporar uma "segunda" lógica na análise da dinâmica dos mercados do conhecimento, ainda que organicamente articulada com a primeira: a disputa por poder existente no âmbito do sistema interestatal capitalista, algo que não se relaciona diretamente com os imperativos do capital pela sua autovalorização, apesar de depender dela em última instância.

Note-se o seguinte: as TIC e a biotecnologia foram os primeiros bens intangíveis do conhecimento a serem monopolizados de maneira sistemática, e continuam ainda hoje se constituindo no mercado do conhecimento mais estratégico. Estes dois campos são frutos de desenvolvimentos científicos e tecnológicos que se devem muito à Segunda Guerra Mundial e, principalmente, à dinâmica da geopolítica durante a Guerra Fria. Nesse período, o desenvolvimento tecnológico e científico - que construiu as condições materiais que hoje permitem a mercantilização do conhecimento em grande escala - respondeu de maneira muito 
mais acentuada à disputa hegemônica entre Estados Unidos e URSS ${ }^{22}$ do que às necessidades diretas de aumentar a subsunção real do trabalho ao capital.

Não se trata de afirmar que há fenômenos explicativos externos ou internos à lógica capitalista, pois o conflito interimperialista necessariamente se inscreve nessa lógica mais geral, mas sim de defender que há elementos históricos que aceleraram de forma extraordinária o desenvolvimento das forças produtivas e que não podem ser explicados somente pelo desenvolvimento "interno" da Grande Indústria.

Desse modo, a explicação do surgimento de um novo paradigma tecnológico que se vale principalmente de análises pertencentes a um alto nível de abstração - como o exame das mudanças nas formas de subsunção do trabalho ao capital, da substância do valor, da natureza do trabalho intelectual, dentre várias outras - é uma tarefa certamente de grande valor, porém insuficiente. Em outras palavras, o autor explicou o desenvolvimento científico e tecnológico que precedeu o atual estágio histórico do capitalismo como resultado estritamente endógeno à dinâmica de funcionamento da Grande Indústria. Trata-se de um trabalho analítico feito com imenso rigor, mas a incorporação da dimensão da luta por poder e hegemonia ${ }^{23}$ (econômica, militar e (geo)política) é fundamental para tornar a crítica da Economia Política do Conhecimento ainda mais profícua e incisiva.

\subsubsection{Mercadoria-conhecimento como fruto da espoliação}

Outra questão de grande relevância é que é necessário reconhecer que nem sempre se pode adotar o suposto de que a produção do conhecimento possui um caráter capitalista. Nem todo conhecimento mercantilizado é produto da subordinação do trabalho intelectual ao capital. Parte significativa do intelecto geral tornada mercadoria é resultado de um amplo processo de espoliação levada a cabo pelo capital, como é o caso da produção científica financiada pelo Estado, dos conhecimentos de comunidades tradicionais privatizados e dos fluxos de dados digitais apropriados gratuitamente - e, muitas vezes, sem consentimento dos seus "donos" pelos grandes monopolistas da informação.

Estes últimos abrangem um verdadeiro universo de espoliação: dados gerados por usuários de internet, por meio dos mecanismos de busca, da navegação na rede, das redes sociais ou por meio do consumo via comércio eletrônico; ou ainda sem o uso tão explícito da grande rede: informações de hábitos gerais e hábitos de consumo produzidos, por exemplo, pelo uso de serviços de cartão de crédito, de aplicativos de transporte e de uma quantidade cada vez maior de serviços. Atualmente, o crescimento da digitalização em esferas do consumo, da produção, da educação, da saúde etc., está a serviço, prioritariamente, do aumento da capacidade de coleta de dados pessoais (Zuboff, 2015). Trata-se, na visão desta autora, do que ela chama de "capitalismo de vigilância", uma variante do capitalismo de informação que

(22) Conforme podemos constatar em Stokes (1997).

(23) Em Ceceña (2002), fica bastante claro que não podemos negligenciar as disputas hegemônicas como elemento crucial para a inteligibilidade do desenvolvimento científico-tecnológico. 
emergiu na última década dando origem a uma nova lógica de acumulação baseada na extração dos dados das populações.

This examination of Varian's combination of data, extraction, and analysis begins to suggest some key features of the new logic of accumulation associated with big data and spearheaded by Google. First, revenues depend upon data assets appropriated through ubiquitous automated operations. These constitute a new asset class: surveillance assets. Critics of surveillance capitalism might characterize such assets as 'stolen goods' or 'contraband' as they were taken, not given, and do not produce [...] appropriate reciprocities (Zuboff, 2015, p. 80-81. Grifos nossos).

O que importa destacar aqui não é exatamente a concepção de "capitalismo de vigilância" da autora; o que importa é que, a partir de suas contribuições, podemos inferir a abrangência e o peso do processo de espoliação levada a cabo pelo grande capital a partir do fenômeno da digitalização sistêmica que ora avança no capitalismo contemporâneo.

Harvey (2003), ao discutir o fenômeno da intensificação da acumulação primitiva no capitalismo contemporâneo, mostra o ineditismo de algumas formas de espoliação como: o patenteamento e licenciamento de material genético; a biopirataria; transformação em mercadoria de formas culturais, históricas e da criatividade intelectual; a corporativização e privatização de bens até agora públicos (como as universidades) etc. Aqui não é preciso entrar no mérito das causas da espoliação para constatar a sua existência.

James Boyle, sob outra perspectiva, ratifica a ideia acima, afirmando que o capitalismo contemporâneo estaria passando por um second enclosure movement, uma analogia entre, de um lado, o cercamento de campos dos primórdios do capitalismo, e de outro, a expansão dos direitos de propriedade intelectual sobre bens públicos intangíveis (Boyle apud Moraes Neto, 2008, p. 2).

$* * *$

Em suma, a análise da natureza da mercadoria-conhecimento é uma condição absolutamente crucial para a compreensão do processo de mercantilização do conhecimento no capitalismo contemporâneo, entretanto este é apenas o primeiro passo. Com base nas substanciais contribuições de Prado e de Teixeira e Rotta e, particularmente, adotando como ponto de partida a tese da ausência de valor das mercadorias-conhecimento defendida por estes últimos, a crítica da economia política contemporânea requer que se faça um desdobramento teórico no qual ganhe maior destaque as categorias do imperialismo e da dependência, incorporando-as à análise de processos históricos relacionados, por exemplo, ao surgimento, consolidação e evolução do regime internacional de propriedade intelectual, bem como à atuação do Estado e das frações burguesas do bloco do poder dos países ricos que monopolizam o conhecimento estratégico. Isso tudo evidencia uma ampla e promissora agenda de pesquisa no campo da Economia Política do Conhecimento e da Informação a partir do arcabouço marxista. 


\section{Referências bibliográficas}

ARBACHE, J. Entrar na era da economia digital garantirá maior crescimento ao Brasil? Não. 2016. Disponível em: http://economiadeservicos.com/2016/05/26/entrar-na-era-da-economiadigital-garantira-maior-crescimento-ao-brasil-nao/. Acesso em: 26 maio 2016.

AS 10 EMPRESAS MAIS VALIOSAS DO MUNDO. Revista Exame. 2018. Disponível em: https://exame.abril.com.br/mercados/as-10-maiores-empresas-mais-valiosas-do-mundo/. Acesso em: 18 dez. 2018.

ASSOCIAÇÃO BRASILEIRA DE LICENCIAMENTO. A ABRAL. 2017. Disponível em: http://abral.org.br/a-abral/. Acesso em: 10 set. 2017.

AZEVEDO, Rita; SELMI, Paula. Amazon e Google ampliam receita e lucro. Valor Econômico. 2018. Disponível em: https://www.valor.com.br/empresas/5950143/amazon-egoogle-ampliam-receita-e-lucro. Acesso em: 18 dez. 2018.

BHATTACHARYA, Rajesh; SEDA-IRIZARRY, Ian. Financialization: a critique of the "autonomization of capital" thesis. New York: John Jay College of Criminal Justice, 2014. (Working Paper, 2014-01).

BRAND FINANCE. Global 500 2018: the annual report on the world's most valuable banking brands. London: BrandFinance, 2018. Disponível em: http://brandfinance.com/images/upload/brand_finance_global_500_report_2018_locked_1.pd f. Acesso em: 02 abr. 2018.

CARCANHOLO, Marcelo Dias; MEDEIROS, João Leonardo. Trabalho no capitalismo contemporâneo: pelo fim das teorias do fim do trabalho. Revista Outubro, n. 20, 2012.

CECEÑA, Ana E. Estrategias de dominación y planos de construcción de la hegemonía mundial. In: GAMBINA, J. La globalización económico financiera. Su impacto en América Latina. Buenos Aires: CLACSO, Consejo Latinoamericano de Ciencias Sociales, 2002. p. 159177.

CECEÑA, Ana E. Estratégias de construção de uma hegemonia sem limites. In: CECEÑA, A. E. (Org.). Hegemonias e emancipações no século XXI. Buenos Aires: Consejo Latinoamericano de Ciencias Sociales - CLACSO, 2005. p. 35-55. Disponível em: http://biblioteca.clacso.edu.ar/clacso/gt/20101018015333/cecena.pdf. Acesso em: 10 set. 2017.

CECEÑA, Ana E.; BARREDA, Andrés. La producción estratégica como sustento de la hegemonía mundial. Aproximación metodológica". In: CECEÑA, Ana. E.; MARÍN, A. B. Producción estratégica y hegemonía mundial. Ciudad de México: Siglo Veintiuno Editores, 1995. p. 15-51.

COMO A MICROSOFT ESTÁ FAZENDO DINHEIRO? Veja o faturamento de cada produto. Canaltech. 2018. Disponível em: https://canaltech.com.br/resultados-financeiros/como-a- 
microsoft-esta-fazendo-dinheiro-veja-o-faturamento-de-cada-produto-75679/. Acesso em: 18 dez. 2018.

CORIAT, B.; ORSI, F. Establishing a new intellectual property rights regime in the United States. Origins, content and problems. Research Policy, v. 31, p. 1491-1507, 2002.

CORIAT, Benjamin; WEINSTEIN, Olivier. Patent regimes, firms and the commodification of knowledge. Socio-Economic Review, v. 10, n. 2, p. 267-292, 2012.

DARDOT, Pierre; LAVAL, Christian. A nova razão do mundo: ensaio sobre a sociedade neoliberal. São Paulo: Boitempo, 2016.

DEBORD, G. A sociedade do espetáculo. São Paulo: Coletivo Periferia, 1967.

DONA DO GOOGLE CRESCE, MAS TEM RECEITA ABAIXO DO ESPERADO PARA O

TERCEIRO TRI. Estadão. 2018.2 Disponível em:
https://link.estadao.com.br/noticias/empresas,dona-do-google-cresce-mas-tem-receita-abaixodo-esperado-para-o-terceiro-tri,70002564122. Acesso em: 18 dez. 2018.

FIORI, José Luís. História, estratégia e desenvolvimento: para uma geopolítica do capitalismo. São Paulo: Boitempo, 2015.

GORZ, André. O imaterial: conhecimento, valor e capital. São Paulo: Annablume. 2005.

GUTIERREZ, Marcelle. Lucro do Facebook cresce 31\% no segundo trimestre. Valor Econômico. 2018. Disponível em: https://www.valor.com.br/empresas/5687621/lucro-dofacebook-cresce-31-no-segundo-trimestre. Acesso em: 18 dez. 2018.

HARDT, Michael; NEGRI, Antonio. Império. Rio de Janeiro: Ed. Record. 2002.

HARVEY, David. O novo imperialismo. São Paulo: Edições Loyola. 2003.

KLEIN, Naomi. Sem logo. A tirania das marcas em um planeta vendido. Rio de Janeiro: Record, 2002.

LENIN, Vladimir. Imperialismo, estágio superior do capitalismo: ensaio popular. São Paulo: Expressão Popular, 2012.

MARINI, R. M. Dialética da dependência. México: Era, 1973. Disponível em: https://goo.gl/yBU4ba. Acesso em: 10 set. 2017.

MARX, Karl. O Capital - Livro I. São Paulo: Boitempo Editorial. 2013.

MARX, Karl. O Capital - Livro III. São Paulo: Boitempo Editorial. 2017.

MARX, K. Grundrisse: manuscritos econômicos de 1857-1858. São Paulo: Boitempo Editorial, 2011.

MORAES NETO, Benedito. O conhecimento como propriedade capitalista: observações sobre o 'second enclosure movement'. In: ENCONTRO NACIONAL DE ECONOMIA, 36, 2008, Salvador. Anais... Niterói: Associação Nacional dos Centros de Pós-graduação em Economia. 
Disponível em: http://www.anpec.org.br/encontro2008/artigos/200807161144080-.pdf. Acesso em: Mar 2015.

ORSI, Fabienne; CORIAT, Benjamin. The new role and status of intellectual property rights in contemporary capitalism. Competition and Change, v. 10, n.2, p. 162-179, 2006.

PAULANI, Leda. Acumulação e rentismo: resgatando a teoria da renda de Marx para pensar o capitalismo contemporâneo. Revista de Economia Política, v. 36, n. 3, p. 514-535, 2016.

PRADO, Eleutério. Desmedida do valor. São Paulo: Xamã. 2005 a.

PRADO, Eleutério. Uma nova fase do capitalismo ou um novo modo de produção capitalista? Revista Outubro, n. 13, p. 47-57, 2005 b.

PRADO, Eleutério. Do que destrói o nosso futuro humano possível. Disponível em: https://eleuterioprado.files.wordpress.com/2016/06/do-que-destroi-o-nosso-futuro-humanopossc3advel.pdf. Acesso em: jun. 2016.

PRADO, Eleutério. Subsunção financeira do trabalho ao capital. Disponível em: https://eleuterioprado.blog/2018/04/17/subsuncao-financeira/. Acesso em: jun. 2018.

RIFKIN, Jeremy. Sociedade com custo marginal zero. São Paulo: M. Books. 2014.

ROTTA, Tomás N. Unproductive accumulation in the USA: a new analytical framework. Cambridge Journal of Economics, v. 42, p. 1367-1392, 2018.

STOKES, Donald E. O quadrante de Pasteur: a ciência básica e a inovação tecnológica. Campinas: Editora da Unicamp, 1997. (Clássicos da Inovação).

TEIXEIRA, Rodrigo A. A produção capitalista do conhecimento e o papel do conhecimento na produção capitalista: uma análise a partir da teoria marxista do valor. Revista EconomiA, v. 10, n. 2, p. 421-456, 2009.

TEIXEIRA, Rodrigo A.; ROTTA, Tomas N. Valueless knowledge-commodities and financialization: productive and financial dimensions of capital autonomization. Review of Radical Political Economics, v. 44, n. 1, p. 448-467, 2012.

UNITED Nations Conference on Trade and Development. World investment report. New York, NY: United Nations, 2017.

ZUAZO, Natalia. Los dueños de internet. Cómo nos dominan los gigantes de la tecnología y qué hacer para cambiarlo. Buenos Aires: Debate, 2018.

ZUBOFF, Shoshana. Big other: surveillance capitalism and the prospects of an information civilization. Journal of Information Technology, v. 30, n. 1, p. 75-89, 2015. 